\title{
Survey of selenium requirements in marine phytoplankton
}

\author{
P. J. Harrison, P. W. Yu, P. A. Thompson, N. M. Price, D. J. Phillips \\ Departments of Oceanography and Botany, The University of British Columbia, Vancouver, British Columbia, Canada V6T 2B1
}

\begin{abstract}
A survey of 27 species of marine phytoplankters, representing 4 algal classes, was conducted to determine if selenium was required for growth. The species were grown in natural and artificial seawater media to which $10^{-8} \mathrm{MNa}_{2} \mathrm{SeO}_{3}$ was added (controls) and in artifical seawater with no Se addition. Fifteen out of 20 species of diatoms tested required Se for growth. Eight out of 9 oceanic diatoms showed an apparent Se requirement. Only 1 (Scrippsiella trochoidea) of the 4 dinoflagellates tested exhibited a similar Se requirement. Two Chrysochromulina spp. and the one Synechococcus sp. grew normally in the artifical seawater medium without added Se. For the species that did not require a Se addition to the artificial seawater medium, it was not possible to determine whether these species have a very low Se requirement that is met by the background Se contamination in the artificial seawater or they actually have no Se requirement. The effect of various Se concentrations $\left(10^{-10}\right.$ to $10^{-7} \mathrm{M}$ ) on growth rates of 4 diatom species ( 3 coastal and 1 oceanic) were examined. The half saturation constant for growth $\left(\mathrm{K}_{\mu}\right)$ was approximately $10^{-9} \mathrm{M}$ Se for all 4 species.
\end{abstract}

\section{INTRODUCTION}

Almost 20 yr ago, Pintner \& Provasoli (1968) demonstrated that Se stimulated the growth of 3 marine Chrysochromulina spp. These very interesting early observations were not pursued further until recently. It is now known that among marine algae, growth of some species of Bacillariophyceae, Chlorophyceae, Phaeophyceae, Rhodophyceae, Prymnesiophyceae and Prasinophyceae is enhanced by or dependent upon Se (Pinter \& Provasoli 1968, Fries 1982, Wheeler et al. 1982, Keller et al. 1984, Keller et al. 1987, Price et al. 1987). Likewise, freshwater algae in the Dinophyceae, Bacillariophyceae, Chlorophyceae and Prymnesiophyceae also require Se for growth (Lindström \& Rhode 1978, Lindström 1983, 1985, Wehr \& Brown 1985). In spite of the seemingly comprehensive list of marine algal groups reported to require $\mathrm{Se}$, there are a number of notable omissions. Foremost among these are the Dinophyceae and Cyanophyceae which include some important primary producers. Documented cases of Se essentiality among marine plankters are limited to coastal organisms, and requirements for Se by phytoplankton indigenous to the open ocean where dissolved Se concentrations are an order of magnitude lower than coastal waters (Measures \& Burton 1980) are unknown. Furthermore, the extent to which Se is required for growth by members in a particular algal class is still unclear because so few species have been examined. These deficiencies in our knowledge underline the importance for further research into the Se requirements of marine phytoplankton.

This article examines the Se requirement for growth of 27 marine phytoplankters, including oceanic species, from 4 algal classes. In addition, the effects of Se concentration on the growth rates of 4 diatoms is reported.

\section{MATERIALS AND METHODS}

Cultures and media. All cultures were obtained from the Northeast Pacific Culture Collection (NEPCC), Department of Oceanography, The University of British Columbia, Vancouver, Canada, where they were maintained in nutrient enriched (without Se) natural seawater (ESNW), i.e. selenium concentrations ranging from $10^{-9}$ to $10^{-10} M$ Se (Cutter \& Bruland 1984). There were 27 species or clones tested of which 20 were diatoms, 4 dinoflagellates, 2 prymnesiophytes and 1 cyanophyte (Table 1). All cultures were unialgal, but precautions were taken to minimize bacterial contamination. Previous research in our laboratory has shown that the stimulatory effect of Se on growth of Thalassiosira pseudonana in xenic unialgal or axenic 
Table 1. Survey of Se requirement for growth in 27 species or clones of marine phytoplanktoners. NEPCC $=$ Northeast Pacific Culture Collection, Dept Oceanography, Univ. British Columbia, Vancouver. Se requirement was determined by growing cultures in artificial seawater medium at a single Se concentration of $10^{-8} M$ Se $\left(a s \mathrm{Na}_{2} \mathrm{SeO}_{3}\right.$ ) for 1 to 8 transfers in batch culture. ' $\mathrm{No}$ ' Se requirement means that these species may have very low Se requirements met by background Se contamination in ESAW (estimated to be $<10^{-12}$ by Price et al. 1987) or no Se requirement. 'No/Yes' indicates uncertainty over a Se requirement

\begin{tabular}{|c|c|c|c|c|}
\hline Taxa & $\begin{array}{c}\text { NEPCC } \\
\text { No. }\end{array}$ & $\begin{array}{l}\text { Isolation } \\
\text { site }\end{array}$ & $\begin{array}{l}\text { Selenium } \\
\text { requirement }\end{array}$ & $\begin{array}{l}\text { No. of } \\
\text { transfers }\end{array}$ \\
\hline \multicolumn{5}{|l|}{ Bacillariophyceae } \\
\hline Amphipora hyalina & 266 & Coastal & Yes & 2 \\
\hline Cerataulina pelagica & 359 & Coastal & No & 3 \\
\hline Chaetoceros gracilis & 294 & Coastal & No & 5 \\
\hline Chaetoceros debilis & 371 & Coastal & Yes & 2 \\
\hline Chaetoceros pelagica & 617 & Oceanic & Yes & 1 \\
\hline Chaetoceros simplex & 591 & Oceanic & No & 2 \\
\hline Chaetoceros vixvisibilis & 613 & Oceanic & Yes & 1 \\
\hline Coscinodiscus asteromphalus & 281 & Coastal & Yes & 2 \\
\hline Corethron criophilum & 506 & Oceanic & Yes & 2 \\
\hline Cylindrotheca closterium & 424 & Coastal & No & 5 \\
\hline Ditylum brightwellij & $8 a$ & Coastal & Yes & 1 \\
\hline Skeletonema costatum & $18 \mathrm{c}$ & Coastal & Yes & 2 \\
\hline Skeletonema costatum & 611 & Oceanic & Yes & 2 \\
\hline Skeletonema costatum & 616 & Oceanic & Yes & 1 \\
\hline Stephanopyxis palmeriana & 615 & Oceanic & Yes & 3 \\
\hline Thalassiosira pseudonana & 58 & Coastal & Yes & 2 \\
\hline Thalassiosira oceanica & 610 & Oceanic & Yes & 2 \\
\hline Thalassiosira rotula & 614 & Oceanic & Yes & 1 \\
\hline Thalassiosira aestivalis & 561 & Coastal & Yes & 5 \\
\hline Thalassiosira weissflogii & 418 & Coastal & No & 8 \\
\hline \multicolumn{5}{|l|}{ Dinophyceae } \\
\hline Gymnodinium simplex & $119 a$ & Coastal & No & 5 \\
\hline Gymnodinium sanguineum & 354 & Coastal & No & 2 \\
\hline Katodinium rotundatum & 44 & Coastal & No/Yes & 3 \\
\hline Scrippsiella trochoidea & 602 & Coastal & Yes & 3 \\
\hline \multicolumn{5}{|l|}{ Prymnesiophyceae } \\
\hline Chrysochromulina ericina & $109 \mathrm{a}$ & Coastal & No & 3 \\
\hline Chrysochromulina polylepis & 242 & Coastal & No & 3 \\
\hline \multicolumn{5}{|l|}{ Cyanophyceae } \\
\hline Synechococcus sp. & 549 & Oceanic & No & 3 \\
\hline
\end{tabular}

cultures was identical (Price et al. 1987), but future work should determine if this lack of a bacterial effect can be unequivocally extended to the phytoplankton species in this study

Natural and artificial seawater was used in the experiments. The natural seawater ( $S=28 \%$ ) was collected at one time from $10 \mathrm{~m}$ depth at the West Vancouver Fisheries Laboratory and filtered through a $0.45 \mu \mathrm{m}$ membrane filter. The artificial seawater, prepared with reagent grade chemicals and deionized distilled water (DDW), was based on ESAW (Harrison et al. 1980) and is described in detail elsewhere (Price et al. 1987). Part of the artificial seawater was enriched with ES nutrient stock solution minus Se (Price et al. $1987)$ and filter sterilized $(0.45 \mu \mathrm{m})$ just prior to inoculating the medium with culture. This artifical seawater medium without Se was termed ESAW-Se. Selenium was added as selenite $\left(\mathrm{Na}_{2} \mathrm{SeO}_{3}\right)$ to the other portion of the artificial seawater and the natural seawater to a concentration of $10^{-8} \mathrm{M}$ and this artificial seawater medium was termed ESAW + Se and the enriched natural seawater was termed ESNW + Se. Both natural and artificial seawater were stored in the dark in separate 2001 polypropylene barrels at $15^{\circ} \mathrm{C}$.

Borosilicate $50 \mathrm{ml}$ screw-capped test tubes with teflon liners were used for culturing. The tubes were cleaned by soaking them in $1 \mathrm{~N} \mathrm{HCl}$ for $24 \mathrm{~h}$, rinsing in DDW, autoclaved with DDW in them and autoclaved again dry.

Selenium requirement experiments. Stock cultures growing in natural seawater were transferred to ESAW-Se and to the 2 controls, ESAW + Se and $E S N W+S e$ (i.e. Se was added at one concentration. $10^{-8} \mathrm{M}$. Cultures were incubated at $18^{\circ} \mathrm{C}$ with $\mathrm{ca}$ $100 \mu \mathrm{E} \mathrm{m}^{-2} \mathrm{~s}^{-1}$ of continuous light. Growth was followed by measuring in vivo chl a fluorescence with a Turner 
Designs Fluorometer (Model 10-100 R) approximately once per day. In late exponential or early scenescent phase batch cultures in the test tubes were serially transferred into new medium for 3 to 6 transfers, or fewer transfers if the cells reached Se limitation (i.e. reduced growth rate and morphological changes! Since stock cultures were maintained in natural seawater (Se ranging from ca $10^{-9}$ to $10^{-10} \mathrm{M}$, and the culture medium was reduced about 100 times with each transfer, then carry-over of Se from the stock medium should not affect these experiments. Treatments were usually run in triplicate and tubes were shaken daily.

Cells were observed periodically with a light microscope to determine if changes in morphology had occurred. Photomicrographs of these morphological changes were taken for some species.

To further demonstrate that Se was required for growth, Se was added back to the ESAW-Se cultures when fluorescence and cell morphology indicated that the cultures were Se limited. Selenium was added to $10^{-8} \mathrm{M}$ and the increase in fluorescence over time was followed to monitor cell growth and determine if the cultures had recovered.

Growth rate experiments. The effect of Se concentration on growth rate was determined by culturing the species as described above, except that Se was added at a range of concentrations, $10^{-10}, 10^{-9}, 10^{-8}$, and $10^{-7}$ $M$. Growth rates were determined from the linear portion of the fluorescence in a plot of log fluorescence vs time, usually after the third or fourth transfer. Since fluorescence per cell is constant during exponential growth, growth rates determined from changes in fluorescence are the same as rates determined from changes in cell number (Price et al. 1987). Students' $t$ test was used to test for statistically significant differences in growth rates.

\section{RESULTS}

\section{Species requirements}

Twenty species or clones of diatoms were tested for $\mathrm{Se}$ requirement. Fifteen were found to require $\mathrm{Se}$, and 8 out of 9 oceanic diatoms showed a Se requirement (Table 1). Se requirement was further documented in Se 'add-back' experiments. Twelve of the 15 species began to grow again when $10^{-8} \mathrm{MNa}_{2} \mathrm{SeO}_{3}$ was added to culture. A typical decrease in the growth rate and the subsequent recovery after Se was added back to the medium is shown for Chaetoceros pelagica (Fig. 1). Five diatoms showed no change in growth rate in the ESAW-Se medium, even after 5 transfers (Table 1).

Four dinoflagellates were also tested (Table 1). None

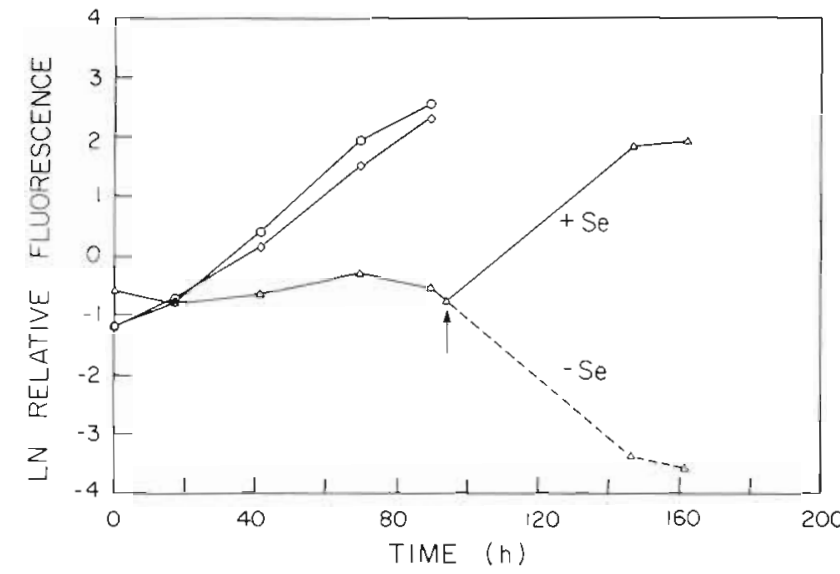

Fig. 1. Chaetoceros pelagica. Growth in (o) naturâl seawater, $(\diamond)$ artificial seawater plus Se and ( $\Delta$ ) artificial seawater (ESAW) minus Se during first transfer Arrow: ESAW-Se culture was split into 2 subcultures, and $\mathrm{Na}_{2} \mathrm{SeO}_{3}\left(10^{-8} \mathrm{M}\right)$ was added to one of the cultures (+Se), no Se to the other $(-\mathrm{Se})$

of the species showed as clear a response as was seen with the diatoms. Katodinium rotundatum required a Se addition for growth in 2 experiments, but no requirement in further tests. Scrippsiella trochoidea showed a significantly $(p<0.05)$ reduced growth rate $\left(\mu=0.5 \pm 0.05 \mathrm{~d}^{-1}\right.$ compared to the control growth rate of $\mu=0.7 \pm 0.02 \mathrm{~d}^{-1}$ ) and cell yield in ESAW-Se. In ESAW-Se, Gymnodinium simplex and $G$. sanguineum grew as well as the control cultures.

Representatives from 2 other algal classes, Chrysochromulina polylepis and $C$. ericina (Prymnesiophyceae) and Synechococcus sp. (Cyanophyceae), showed no reduction in growth rate in ESAW-Se after 3 transfers.

\section{Cell morphology}

The diatoms responded to Se limitation by increasing their cell volume, primarily through a large increase in cell length of 2 to 5 times the normal length (Fig. 2). Cells were also often arched or curved. An exception to this general response was shown by the pennate diatom, Amphiprora hyalina. Cell width in the Sedeplete cultures was less $(3.2 \pm 1.2 \mu \mathrm{m}, n=50, \pm 2 \mathrm{SD})$ than normal Se-replete cells $(5.5 \pm 0.8 \mu \mathrm{m}, n=50, \pm 2$ $\mathrm{SD}$ ) resulting in a decrease in cell volume. The dinoflagellate, Scrippsiella trochoidia, showed no visible morphological changes due to Se limitation.

\section{Effects of Se on growth rate}

Effects of Se concentrations ranging from $10^{-10}$ to $10^{-7}$ $M$ were tested on 4 algal species. Ditylum brightwellii showed a significant $(p<0.05)$ reduction in growth rate at Se concentrations of $10^{-9} \mathrm{M}$ or less (Fig. $3 \mathrm{~A}$ ). Assum- 

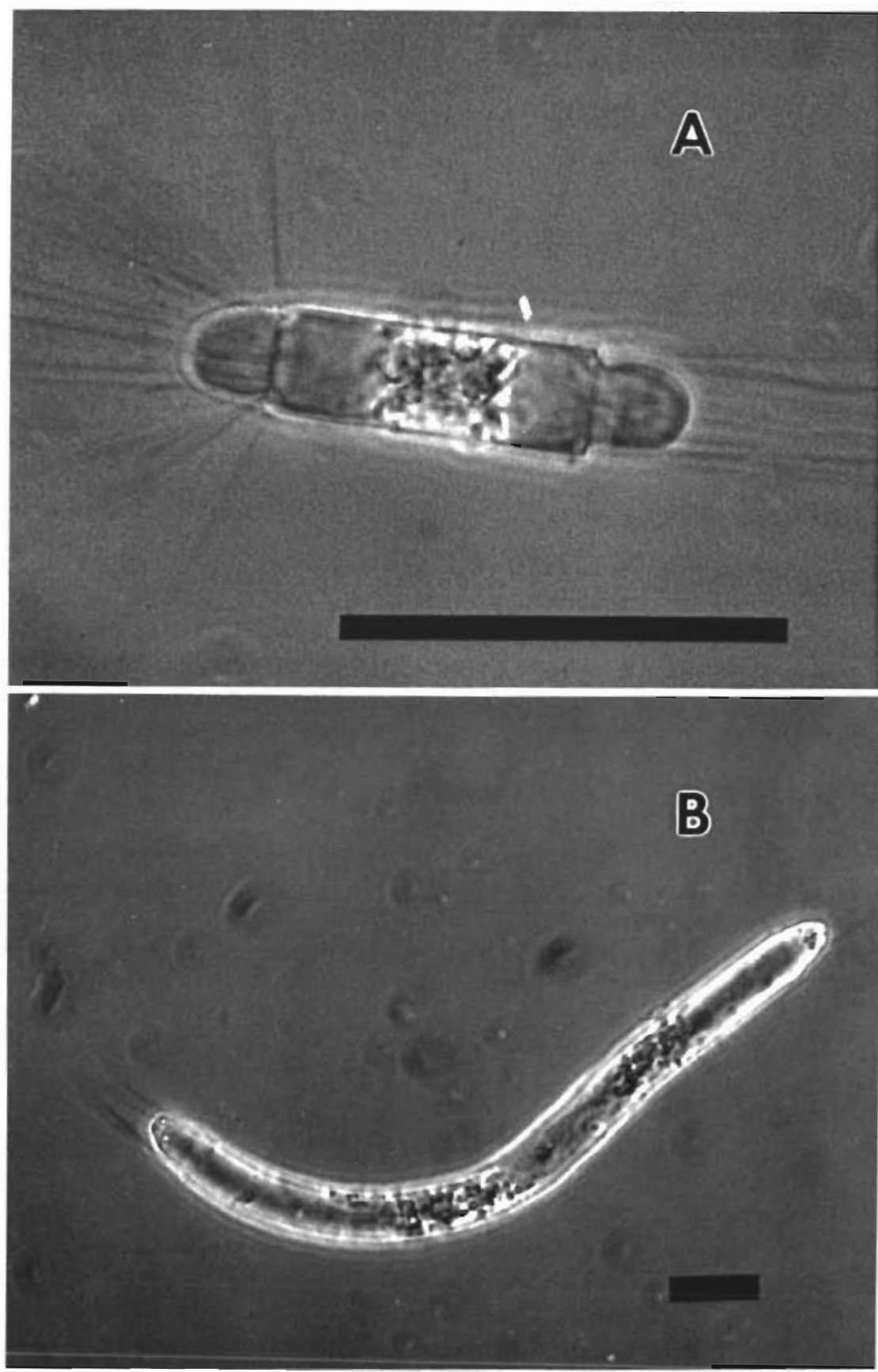

Fig. 2. Corethron criophilum. Photomicrographs of vegetative cells of this oligotrophic diatom, qrown in artificial seawater. (A) $\mathrm{ESAW}+\mathrm{Se}\left(10^{-8} \quad M \mathrm{Se}\right)$; (B) - Se Scale bars $=5 u \mathrm{~m}$

ing that a rectangular hyperbola can be fit to these data, $K_{\mu}$ is estimated to be approximately $10^{-10} \mathrm{M}$ (Fig. 3B). Similarly, the growth rate of Skeletonema costatum (a coastal clone) was reduced at $10^{-9} \mathrm{M}$ Se or less (Fig. 4B). It is also interesting to note that the reduction in growth rate was not apparent up until the third transfer (Fig. 4A). This observation points out the importance of allowing sufficient adaptation time to reduce intracellular Se concentrations. An oceanic clone of $S$. costatum (NEPCC \# 611) was also grown at a range of Se concentrations. Unfortunately, all the cultures died during the third transfer for unknown reasons and repeated attempts to grow this clone beyond 3 transfers were unsuccessful.

In the other tests, a pair of coastal and oceanic clones were grown to determine if there was a difference in their Se requirements. Thalassiosira pseudonana (coastal clone, $3 \mathrm{H}$ ) and $T$ oceanica (oceanic clone, previously referred to as $T$. pseudonana, clone 13-1) were also compared. The oceanic clone grew at very low Se concentrations $\left(10^{-10} \mathrm{M}\right.$ ) but the maximum growth rate was only realized at higher Se concentrations $\left(>10^{-9}\right.$ 

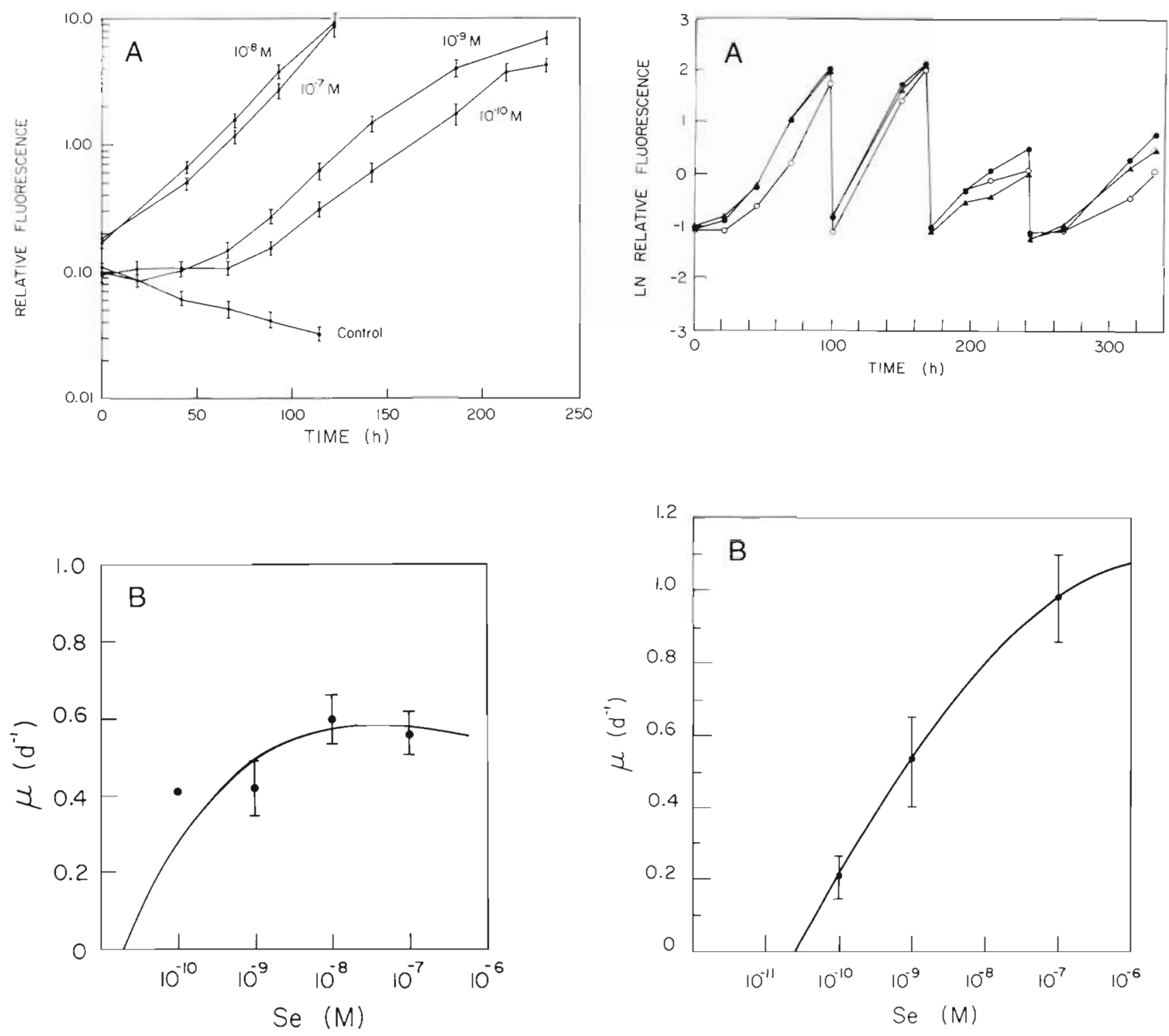

Fig. 3. Ditylum brightwellii. (A) Growth in artificial seawater containing a range of Se concentrations $\left(10^{-10}\right.$ to $\left.10^{-7} \mathrm{M}\right)$ during first transfer. Control: no Se addition; error bars: \pm $1 \mathrm{SD}$ and $n=3$. (B) Growth rate vs Se concentration. Curves drawn by eye; error bars: $\pm 1 \mathrm{SD}$ and $n=3$

M) (Fig. 5A, B). The coastal clone did not grow in ESAW supplemented with $10^{-10} \mathrm{MSe}$, but at $10^{-9} \mathrm{MSe}$ it grew near maximal rates (Fig. 5C, D).

\section{DISCUSSION}

\section{Species requirements}

As a group, diatoms gave the clearest indication of a definite Se requirement, although more species of

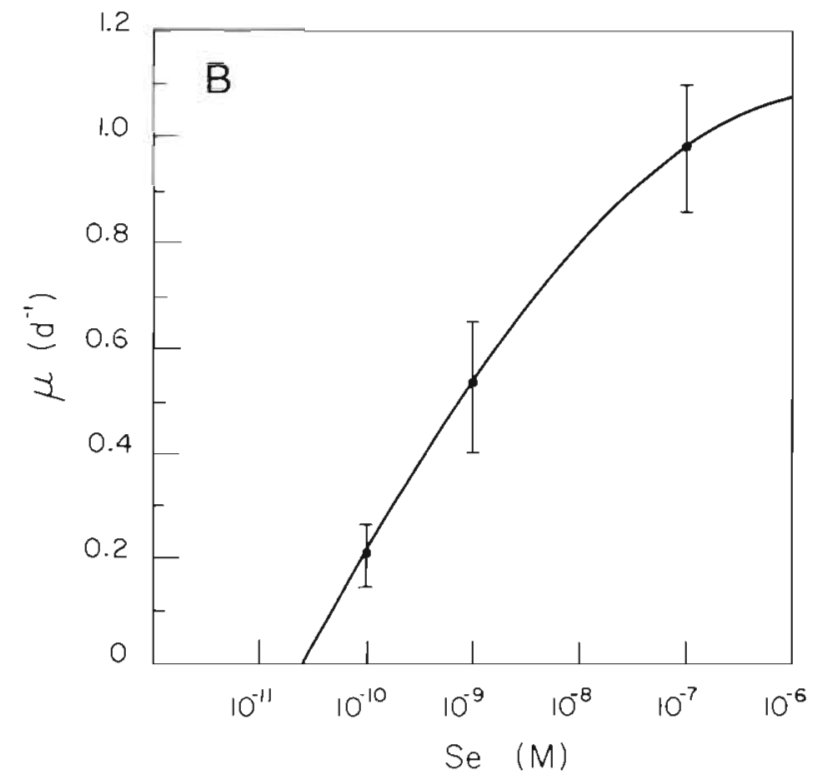

Fig. 4. Skeletonema costatum. (A) Growth of coastal clone, $3 \mathrm{H}$, in artificial seawater with $10^{-9} M$ Se over 4 transfer periods in triplicate cultures. (B) Growth rate (average of third and fourth transfers) vs Se concentration. Error bars: $\pm 1 \mathrm{SD}$ and $n=3$

diatoms were tested than representatives from other algal classes. Therefore, it is possible to conclude that except for a few species, Se is apparently an essential element for diatoms. The rapidity of the response to Sedeplete medium varied with the species and depended upon the preparation of the artificial seawater medium. At the beginning of this project, some species required 5 transfers in ESAW-Se before their growth rate was reduced. Later in the study, an increased effort to prevent Se contamination, reduced growth rates during the second transfer. To prevent this variability in 

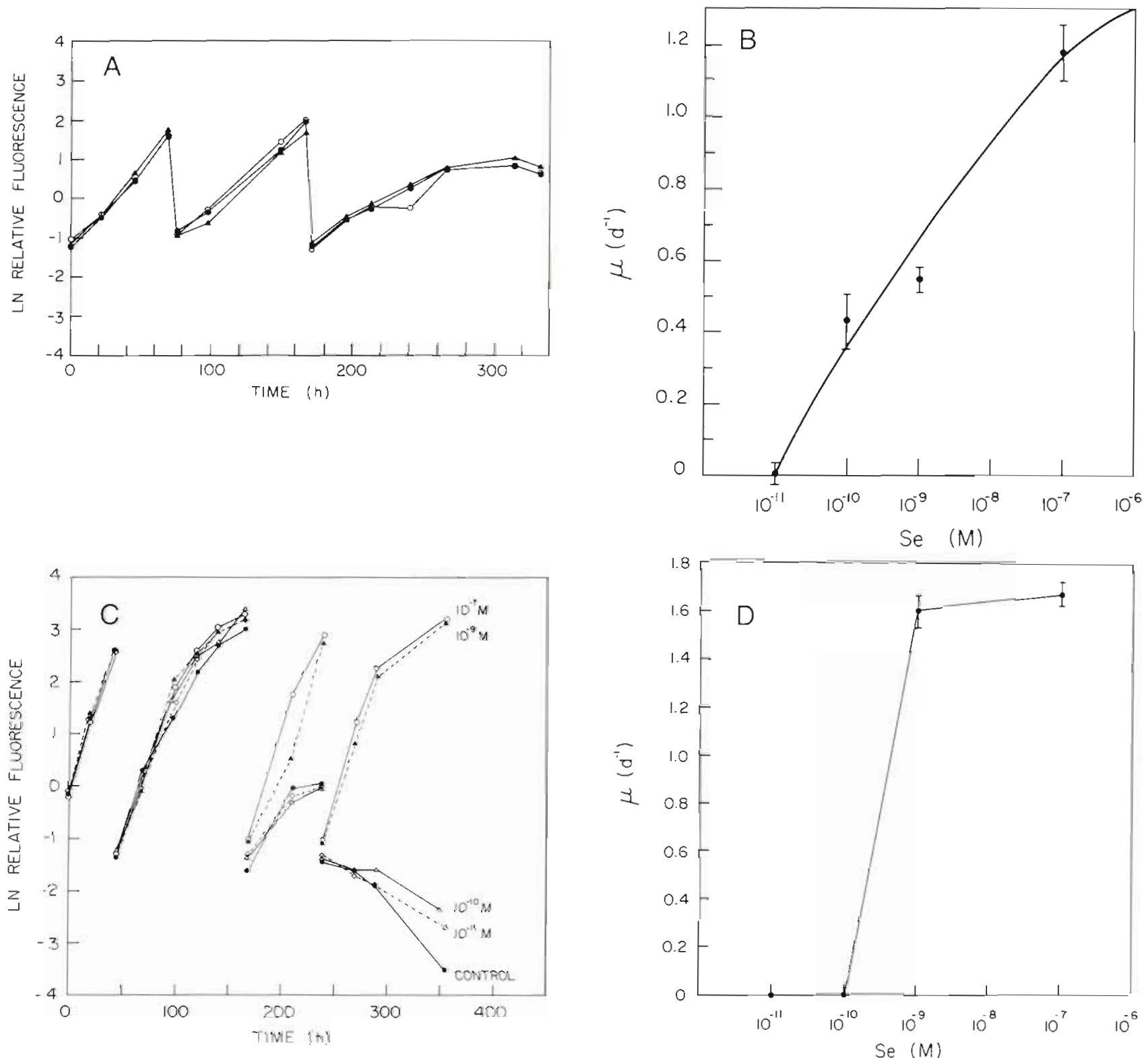

Fig. 5. Thalassiosira. (A) Growth of $T$ oceanica (oceanic clone) in artificial seawater with 10 " $M$ Se over 3 transfer periods in triplicate cultures. (B) Growth rate (third transfer period) of $T$ oceanica vs Se concentrations; error bars: $\pm 1 \mathrm{SD}$ and $n=3$. (C) Growth of $T$ pseudonana (coastal clone) in artificial seawater with a range of Se concentrations over 4 transfer periods $(n=3)$; at In fluorescence $=1$, cell density is $2.55 \pm 0.015 \times 10^{8}$ cells $1^{-1}$ (D) Growth rate (fourth transfer period) of $T$ pseudonana vs Se concentrations; error bars: $\pm 1 \mathrm{SD}$ and $n=3$

background contamination of Se, one large batch of seawater was prepared and used throughout this study. Price et al. (1987) have also discussed variability in results due to variations in medium preparation.

Twelve of the 15 species that exhibited reduced growth rates in ESAW-Se medium resumed maximal growth when Se was added back to the medium. Some species showed a substantial lag (up to 7 d) before responding to the re-addition of Se. We also found that if Se-starved cultures were left too long (e.g. $>5 \mathrm{~d}$ ) they would not respond to the Se addition. This obser- vation suggests that Se limitation is similar to silicate limitation in that it is more difficult for a cell to recover from these 2 limitations than from nitrogen or phosphorus limitation (Parslow et al. 1984)

The 5 diatoms that showed no reduced growth in ESAW-Se and no cellular morphological changes symptomatic of Se limitation must have very low Se requirements that are met by the background Se contamination in ESAW, or they have no requirements for Se. Of course, this will also be true for the other phytoplankton groups (e.g. dinoflagellates, chrysophytes, 
cyanobacteria, etc.) discussed below. Results from Se add back experiments with Thalassiosira pseudonana in our laboratory indicate that the background concentration of Se in the artificial seawater was probably $10^{-12} M$ Se (Price et al. 1987).

The response of dinoflagellates to ESAW-Se was variable. Only 1 species, Scrippsiella trochoidea, had a reduced growth rate. Katodinium rotundum showed reduced growth in 2 out of 4 experiments, but in recent experiments using a different batch of ESAW-Se, it exhibited no reduction in growth rate at Se concentrations as low as $10^{-11} \mathrm{M}$ (Clifford 1987). Two freshwater dinoflagellates, Peridinium cinctum and Peridinopsis borgei, have been shown to require Se (Lindström \& Rhode 1978, Lindström 1983, Lindström 1985).

We were surprised that Chrysochromulina polylepis and $C$. ericina did not show a Se requirement because the freshwater species $C$. breviturrita has been shown to have a clear Se requirement (Wehr \& Brown 1985). In addition, the first marine phytoplankton shown to require Se were Chrysochromulina spp. (Pintner \& Provasoli 1968).

\section{Cell morphology}

The dramatic increase in cell length of the Se-limited centric diatoms in this study is similar to that reported by Price et al. (1987) for Thalassiosira pseudonana. These observations on visible morphological changes were extended to the ultrastructural level by Doucette et al. (1987). They found in Se-deplete $T$. pseudonana that cell elongation involved the blockage of both mitotic and cytokinetic components of cell division and that Se deficiency resulted in ultrastructural alterations in the reticular membrane system and in mitochondrial and chloroplast membranes.

Contrary to centric diatoms, the one pennate that we studied decreased its cell width while its length remained constant, resulting in a decrease in cell volume. This is the first report of morphological changes induced by Se deficiency in a pennate diatom and further work is required to determine if other pennates follow a similar pattern.

\section{Effects of Se on growth rate}

Three coastal diatoms grown in ESAW containing Se ranging from $10^{-10} \mathrm{M}$ to $10^{-7} \mathrm{M}$ Se showed a reduction in growth rate at $10^{-9} \mathrm{M}$ Se or less. Only Thalassiosira pseudonana did not grow at $10^{-10} \mathrm{M}$. Price et al. (1987) also studied the coastal clone of $T$. pseudonana but they found no reduction in growth rate at $10^{-10} \mathrm{MSe}$, but cell yield, measured by fluorescence, was reduced. One plausible explanation for this difference between our results and their results is that they may have had a higher background level of Se in their artificial seawater.

The one oceanic species studied, Thalassiosira oceanica, exhibited a very similar response in growth rate with varying Se concentrations compared to the 3 coastal species. The Se requirements for coastal and oceanic diatoms appear to be similar, but further tests with more clones are required to confirm this possibility. The $K_{\mu}$ value for growth for all 4 species is ca $10^{-9} \mathrm{M}$ $\mathrm{SeO}_{3}{ }^{-2}$-Se. The concentration of total Se in oligotrophic oceanic surface seawater averages $5 \times 10^{-10} \mathrm{~mol} \mathrm{~kg} \mathrm{~kg}^{-1}$ and $80 \%$ of this is dissolved organic selenide (Measures \& Burton 1980, Cutter \& Bruland 1984). Our preliminary results on growth rate at different Se concentrations indicate that the growth rate of some oligotrophic phytoplankton species could possibly be Selimited in oligotrophic areas of the ocean. This possibility warrants further investigation.

For a freshwater dinoflagellate, Peridinium cinctum, an addition of $2.5 \times 10^{-13} \mathrm{M}$ Se has been observed to stimulate the growth of this species (Lindström \& Rhode 1978); the $\mathrm{K}_{\mu}$ for this species was $10^{-10} \mathrm{MSe}$. Other algal species have been reported to require considerably higher concentrations of Se for growth. Platymonas spp. grew better than controls only when Se concentrations greater than $1.3 \times 10^{-5} \mathrm{M}$ were added to the medium (Wheeler et al. 1982).

Brand et al. (1983) examined the effect of varying concentrations of iron, manganese and zinc on the growth rate of coastal and oceanic phytoplankton species. Their results showed that the oceanic species required an order of magnitude less iron for growth than the coastal species, but there was no significant difference between the requirements for $\mathrm{Mn}$ and $\mathrm{Zn}$ by coastal and oceanic species. We were not able to test enough oceanic and coastal clones to determine if there is a clear difference in the Se concentration requirements between coastal and oceanic clones. However, our preliminary results suggest that coastal and oceanic species of phytoplankton may require a similar concentration of selenite for growth. Further research is now necessary to examine other oceanic species and to assess the importance of selenate $\left(\mathrm{SeO}_{4}{ }^{-2}\right)$ and the hitherto uncharacterized dissolved organic Se compounds for growth of oceanic phytoplankton. Further experiments in the Se physiology of phytoplankton could be significantly improved if they advance to the point of chemically determining the actual Se concentration in the culture medium.

Acknowledgements. This research was supported by the Natural Sciences and Engineering Research Council (NSERC) of Canada. NMP was supported by a NSERC Post-Graduate Scholarhip, and PWY was supported by a student award from 
the provincial government of British Columbia. We thank Dr Elizabeth Cosper and an anonymous referee for their suggestions and for critically reading the manuscript.

\section{LITERATURE CITED}

Brand, L. E., Sunda, W. G., Guillard, R. R. L. (1983). Limitation of marine phytoplankton reproductive rates by zinc, manganese, and iron. Limnol. Oceanogr. 28: 1182-1198

Clifford, P. J. (1987). Utility of a carbon-14 bioassay for detecting selenium limitation in marine phytoplankton. M. Sc thesis, University of British Columbia, Vancouver, Canada

Cutter, G. A., Bruland, K. W. (1984). The marine biogeochemistry of selenium: A re-evaluation. Limnol. Oceanogr. 29: 1179-1192

Doucette, G. J., Price, N. M., Harrison, P. J. (1987). Effects of selenium deficiency on the morphology and ultrastructure of the coastal marine diatom Thalassiosira pseudonana (Bacillariophyceae). J. Phycol. 23: 9-17

Fries, L. (1982). Selenium stimulates growth of marine macroalgae in axenic culture. J. Phycol. 18: 328-331

Harrison, P. J., Waters, R. E., Taylor, F. J. R. (1980). A broad spectrum artificial seawater medium for coastal and open ocean phytoplankton. J. Phycol. 16: 28-35

Keller, M., Guillard, R. R. L., Provasoli, L., Pintner, I. J. (1984). Nutrition of some marine ultraplankton clones from the Sargasso Sea. Eos 65: 898

Keller, M. D., Selvin, R. C., Claus, W., Guillard, R. R. L. (1987). Media for the culture of oceanic ultraplankton. J. Phycol. 23: 633-638
Lindström, K (1983). Selenium as a growth factor for plankton algae in laboratory experiments in some Swedish lakes. Hydrobiologia 101: 35-48

Lindström, K. (1985). Selenium requirement of the dinoflagellate Peridinopsis borgei (Lemm). Int. Revue ges. Hydrobiol. 70: 77-85

Lindström, K., Rhode, W (1978). Selenium as a micronutrient for the dinoflagellate Peridinium cinctum fa. westii. Mitt. int. Verein. theor. angew. Limmol. 21: 168-173

Measures, C. I., Burton, J. D. (1980). The vertical distribution and oxidation states of dissolved selenium in the northeast Atlantic Ocean and their relationship to biological processes. Earth Planet. Sci. Lett. 46: 385-396

Parslow, J. S., Harrison, P. J., Thompson, P. A. (1984). Saturated uptake kinetics: transient response of the marine diatom Thalassiosira pseudonana to ammonium, nitrate, silicate or phosphate starvation. Mar. Biol 83: 51-59

Pintner, I. J., Provasoli, L. (1968). Heterotrophy in subdued light of 3 Chrysochromulina species. Bull. Misaki mar. biol. Inst., Kyoto Univ. 12: 25-31

Price, N. M., Thompson, P. A., Harrison, P. J. (1987). Selenium: an essential element for growth of the coastal marine diatom Thalassiosira pseudonana (Bacillariophyceae). J. Phycol. 23; 1-9

Wehr, J. D., Brown, L. M. (1985). Selenium requirement of a bloom-forming planktonic alga from softwater and acidified lakes. Can. J. Fish. Aquat. Sci. 42: 1783-1788

Wheeler, A. E., Zingaro, R. A., Irgolic, K., Bottino, N. R. (1982). The effect of selenate, selenite and sulphate on the growth of six unicellular green algae. J. exp. mar. Biol. Ecol. 57 : 181-194 